\title{
The Price of Gold and the Exchange Rates: Once Again
}

\author{
Larry A. Sjaastad*
}

\begin{abstract}
This paper examines the theoretical and empirical relationships between the major exchange rates and the price of gold using forecast error data. Among other things, it is found that, since the dissolution of the Bretton Woods international monetary system, floating exchange rates among the major currencies have been a major source of price instability in the world gold market and, as the world gold market now seems to be dominated by the U.S. dollar bloc, appreciations or depreciations of that dollar would have strong effects on the price of gold in other currencies. The results of this study are rather different from those obtained in an earlier study of the same subject. (JEL D40, F33)
\end{abstract}

* Professor Emeritus, Department of Economics, University of Chicago and Adjunct Professor, The University of Western Australia and Associate, the Economic Research Centre of the University of Western Australia. 
The main objective of this paper, as in a previous one, is to identify the effect of major currency exchange rates on the prices of internationally traded commodities. ${ }^{1}$ For commodities that are traded continuously in organized markets such as the Chicago Board of Trade, a change in any exchange rate will result in an immediate adjustment in the prices of those commodities in at least one currency, and perhaps in both currencies if both countries are "large". For example, when the dollar depreciates against the euro, dollar prices of commodities tend to rise (and euro prices fall) even though the fundamentals of the markets - all relevant factors other than exchange rates and price levels-remain unchanged. The power of this effect is suggested by the events surrounding the intense appreciation of the dollar from early 1980 until early 1985, during which the U.S. price level rose by 30 per cent but the IMF dollar-based commodity price index fell by 30 per cent, and dollar-based unit-value indices for both imports and exports of commodity-exporting countries as a group declined by 14 per cent. The explanation for this anomaly lies in exchange rates: with respect to the DM, for example, the dollar appreciated in the same period by more than 90 per cent in nominal terms, and by 45 per cent in real terms.

The potential importance of this phenomenon is not limited to the major currency countries. With several minor currencies of the world being directly or indirectly tied to one of the three major currencies (the dollar, the euro, and the yen) or a currency basket, shocks to major currency exchange rates are felt not only by producers and consumers of internationally-traded commodities in major currency countries but also by many of the smaller, commodity-exporting countries in the form of inflationary (or deflationary) shocks transmitted by fluctuations in the international prices of commodities. The idea of the Australian dollar as a "commodity currency" is an example.

In the first of the sections to follow, an international pricing model is developed, which predicts that changes in major currency exchange rates will impact on the prices of commodities in all currencies-major and minor alike. Section II is concerned with preliminary tests of the data and section III - the core of the paper-reports the findings of a study of the international market for gold. A short summary section concludes the paper.

Gold is a prime candidate for a study of the effects on commodity prices of fluctuations in major currency exchange rates. A highly homogeneous commodity, gold is traded almost continuously in well organized spot and future markets. Moreover, as annual production (and consumption) of gold is minuscule compared with the global stock, the gold producing countries, not all of whose currencies are traded in organized markets, are unlikely to dominate the world gold market.

\section{EXCHANGE RATES AND COMMODITY PRICES: THE MODEL}

The model developed in this section focuses on the effect of movements in exchange rates on the international price of a homogeneous commodity that is traded in an organized market; it is not the usual asset pricing model as it is not concerned with the rate of return on holding commodity in question. ${ }^{2}$ The model has two basic elements: the law of one price and global market clearing in a world of $\mathrm{M}$ countries or currency blocs. Ignoring all barriers to trade and with all variables expressed in natural logarithms, the law of one price for an internationally-traded commodity is simply:

(1) $P_{1}=P_{j}+E_{1 j}, j=1, \ldots, M$,

1 To avoid unnecessary rewriting, and since the methodology in this paper is very similar to a previous one, substantial portions of what follows concerning methodology have been reproduced from my "The Price of Gold and the Exchange Rates,” (with Fabio Scacciavillani), Journal of International Money and Finance, December, 1996; reprinted in Meher Manzur (ed.), Exchange Rates, Interest Rates and Commodity Prices, Edward Elgar, 2002, and in MoonJoong Tcha (ed.), Gold and the modern World Economy, Routledge, 2003. The layout of the paper is very similar to the earlier one.

2 To the best of the author's knowledge, Ridler and Yandle (1972) were the first to use this approach to analyze the effect of exchange rate adjustments on commodity prices. The model presented here first appeared in Sjaastad (1985); a similar approach was developed by Dornbusch (1987). 
$P_{j}$ being the commodity price in currency $j$ and $E_{1 j}$ the price of currency $j$ in terms of the reference currency 1. Feedback from the commodity market to exchange rates is assumed to be negligible.

The excess demand (i.e., net imports), $\mathrm{Q}_{\mathrm{j}}$, for that commodity in currency bloc $\mathrm{j}$ is a function of its real price, $\mathrm{P}_{j}^{\mathrm{R}} \equiv \mathrm{P}_{\mathrm{j}}-\mathrm{P}_{\mathrm{j}}^{*}$, where $\mathrm{P}_{\mathrm{j}}^{*}$ is the price level in that bloc, and a 1 by $\mathrm{N}$ vector $\mathrm{X}_{\mathrm{j}}=\left(\mathrm{X}_{\mathrm{j} 1}, \mathrm{X}_{\mathrm{j} 2}, \ldots, \mathrm{X}_{\mathrm{jN}}\right)$ of (yet to be specified) market "fundamentals" specific to the commodity in question and currency bloc $\mathrm{j}$ :

$$
\mathrm{Q}_{\mathrm{j}}=\mathrm{Q}_{\mathrm{j}}\left(\mathrm{P}_{\mathrm{j}}^{\mathrm{R}}, \mathrm{X}_{\mathrm{j}}\right), \partial \mathrm{Q}_{\mathrm{j}} / \partial \mathrm{P}_{\mathrm{j}}^{\mathrm{R}} \leq 0, \mathrm{j}=1, \ldots, \mathrm{M} \text {. }
$$

Global market clearing requires:

$$
\sum_{\mathrm{j}=1}^{\mathrm{M}} \mathrm{Q}_{\mathrm{j}}\left(\mathrm{P}_{\mathrm{j}}^{\mathrm{R}}, \mathrm{X}_{\mathrm{j}}\right)=0
$$

and hence a local log-linear approximation can be written as:

$$
\sum_{\mathrm{j}=1}^{\mathrm{M}}\left(\partial \mathrm{Q}_{\mathrm{j}} / \partial \mathrm{P}_{\mathrm{j}}^{\mathrm{R}}\right) \cdot\left(\mathrm{P}_{\mathrm{j}}^{\mathrm{R}}-\mathrm{P}_{\mathrm{j}}^{-\mathrm{R}}\right)+\sum_{\mathrm{j}=1}^{\mathrm{M}}\left(\sum_{\mathrm{i}=1}^{\mathrm{N}}\left(\partial \mathrm{Q}_{\mathrm{j}} / \partial \mathrm{X}_{\mathrm{ji}}\right) \cdot\left(\mathrm{X}_{\mathrm{ji}}-\overline{\mathrm{X}}_{\mathrm{ji}}\right)\right)=0,
$$

where $\mathrm{P}_{\mathrm{j}}^{-\mathrm{R}}$ and $\overline{\mathrm{X}}_{\mathrm{ji}}$ are means of the distributions of $\mathrm{P}_{\mathrm{j}}^{\mathrm{R}}$ and $\mathrm{X}_{\mathrm{ji}}$.

From equation $1, P_{j}^{R}=P_{1}-E_{1 j}-P_{j}^{*}$, so equation (2) can be rearranged into a fairly simple expression for $\mathrm{P}_{1}$ :

$$
\mathrm{P}_{1}=\text { constant }+\sum_{\mathrm{j}=1}^{\mathrm{M}} \theta_{\mathrm{j}} \cdot\left(\mathrm{E}_{1 \mathrm{j}}+\mathrm{P}_{\mathrm{j}}^{*}\right)+\mathrm{K}(\mathrm{X}),
$$

where $\theta_{j}=\left(\partial Q_{j} / \partial P_{j}^{R}\right) / \sum_{j=1}^{M}\left(\partial Q_{j} / \partial P_{j}^{R}\right)$; while $Q_{j}$ may be positive or negative, $\partial Q_{j} / \partial P_{j}^{R}$ is nonpositive so the $\theta_{\mathrm{j}}$ are non-negative fractions that sum to unity. The global fundamentals are captured by $\mathrm{K}(\mathrm{X})=-\sum_{\mathrm{j}=1}^{\mathrm{M}} \sum_{\mathrm{i}=1}^{\mathrm{N}}\left[\left(\partial \mathrm{Q}_{\mathrm{j}} / \partial \mathrm{X}_{\mathrm{ji}}\right) \cdot \mathrm{X}_{\mathrm{ji}}\right] / \sum_{\mathrm{j}=1}^{\mathrm{M}}\left(\partial \mathrm{Q}_{\mathrm{j}} / \partial \mathrm{P}_{\mathrm{j}}^{\mathrm{R}}\right)$; i.e., $\mathrm{X}$ is a vector containing all elements of the country-specific $X_{j}$ vectors. ${ }^{3}$ Since $P_{k}=P_{1}-E_{1 k}$ and $E_{k j}=E_{1 j}-E_{1 k}$, equation 3 can be specified in any currency $k: P_{k}=$ constant $+\sum_{j=1}^{M} \theta_{j} \cdot\left(E_{k j}+P_{j}^{*}\right)+K(X)$. Changes in the global fundamentals have identical effects on the price of the commodity in question regardless of currency of denomination.

By subtracting $\mathrm{P}_{1}^{*}$ from both sides of equation 3 we obtain:

$$
\mathrm{P}_{1}^{\mathrm{R}}=\sum_{\mathrm{j}=1}^{\mathrm{M}} \theta_{\mathrm{j}} \cdot \mathrm{E}_{1 \mathrm{j}}^{\mathrm{R}}+\mathrm{K}(\mathrm{X}) \text {, }
$$

where $E_{1 j}^{R} \equiv E_{1 j}+P_{j}^{*}-P_{1}^{*}$ is the purchasing-power-parity (PPP) real exchange rate between currency blocs 1 and $\mathrm{j}$. For the commodity in question, then, $\theta_{\mathrm{j}}$ is simultaneously the elasticity of its nominal price in currency bloc 1 with respect to the nominal exchange rate (or price level) of bloc $\mathrm{j}$, and the elasticity of its real price in currency bloc 1 with respect to the PPP real exchange rate between blocs 1 and $\mathrm{j}$, holding all other variables constant in both cases. While the $\theta_{\mathrm{j}}$ can be estimated with either nominal or real variables, the actual estimation will use forecast errors.

IA. An Interpretation of the "Thetas"

The "thetas" in equation 3 are key to the analysis as they measure the relative market power

3 Global fundamentals are defined as all factors other than exchange rates and price levels that influence the global demand for and supply of the commodity in question, including expectations. 
possessed by each participant in the world market for the commodity in question. Consider a small depreciation of currency 1 against all other currencies (holding all $\mathrm{P}_{\mathrm{j}}^{*}$ constant); the effect of that depreciation on $P_{1}$ is $\sum_{j=2}^{M} \theta_{j}=1-\theta_{1}$. If currency bloc 1 is a price taker in, say, the world gold market, that depreciation will have no effect on the price of gold in other currencies so the entire impact falls on the price of gold in currency 1 and hence $\theta_{1}=0$. In other words, currency bloc 1 is the classic "small" economy in the world gold market. On the other hand, if bloc 1 is an absolute price maker, that depreciation will have no effect on the price of gold in currency 1 as that bloc totally dominates the world gold market, so $\theta_{1}=1$; all of the effect of the depreciation will appear in the price of gold in all other currencies.

To dominate the world market for any commodity, a country must have an extremely elastic excess demand for that commodity. When stocks are small compared with annual production and consumption (as in the case of wheat or copper), a country must be a major producer and/or consumer in order to dominate the price of a commodity. Precious metals are unusual in that stocks are very large compared with annual production and/or consumption and hence a country with a high propensity to hoard gold might dominate the world gold market without being a major or even minor producer.

Given the high variability of major currency exchange rates since 1973, the term $\sum_{\mathrm{j}=1}^{\mathrm{M}} \theta_{\mathrm{j}} \cdot\left(\mathrm{E}_{1 \mathrm{j}}+\mathrm{P}_{\mathrm{j}}^{*}\right)$ of equation 3 is a potentially important source of shocks to the price of a commodity such as gold, and hence estimates of the $\theta_{\mathrm{j}}$ can be useful. ${ }^{4}$ That information can help identify the sources (exchange rates versus the fundamentals) of the price shocks experienced by consumers and producers of gold; to the extent that exchange rates can be predicted, one can forecast the effects of movements in those rates on the price of gold. Finally, information about the $\theta_{\mathrm{j}}$ can be exploited for portfolio management; by denominating their assets and liabilities in foreign currency in accordance with the $\theta_{\mathrm{j}}$, firms involved in gold production can reduce the financial impact of exchange rate shocks.

\section{IB. The Forecast Error Approach}

With appropriate time series data, the $\theta_{j}$ coefficients in equation 3 can be estimated, but that procedure confronts long standing issues such as the stationarity of exchange rates. However, when the currencies and commodities are traded in both spot and forward markets, those issues can be finessed by using forecast errors, which involves writing equation 3 in terms of those errors extracted from spot and forward price and exchange rate data rather than with actual prices and exchange rates. As forecast error data typically are stationary and, if the relevant markets are "efficient", and serially uncorrelated as well, the econometric analysis can be considerably simplified.

To develop this approach, we begin with spot and forward versions of equation 3 (3S); apart from notation, the former is identical with equation 3 :

$$
\mathrm{P}_{1, \mathrm{t}}^{\mathrm{S}}=\text { constant }+\sum_{\mathrm{j}=1}^{\mathrm{M}} \theta_{\mathrm{j}} \cdot\left(\mathrm{E}_{1 \mathrm{j}, \mathrm{t}}^{\mathrm{S}}+\mathrm{P}_{\mathrm{j}, \mathrm{t}}^{*}\right)+\mathrm{K}^{\mathrm{S}}\left(\mathrm{X}_{\mathrm{t}}\right) \text {, }
$$

and the forward version $(3 F)$ is written as:

$$
\mathrm{P}_{1, \mathrm{t}, \mathrm{n}}^{\mathrm{F}}=\text { constant }+\sum_{\mathrm{j}=1}^{\mathrm{M}} \theta_{\mathrm{j}} \cdot\left(\mathrm{E}_{1 \mathrm{j}, \mathrm{t}, \mathrm{n}}^{\mathrm{F}}+\mathrm{P}_{\mathrm{j}, \mathrm{t}, \mathrm{n}}^{* \mathrm{~F}}\right)+\mathrm{K}^{\mathrm{F}}\left(\mathrm{X}_{\mathrm{t}}\right),
$$

\footnotetext{
See Frenkel (1981) concerning the large fluctuations in PPP, and hence in PPP real exchange rates, experienced by the major currencies during the 1970s and Edwards (1989) for a massive compilation of real exchange rate data for smaller countries.
} 
where the $\mathrm{S}$ and $\mathrm{F}$ superscripts denote spot and forward, $\mathrm{P}_{\mathrm{j}}^{* \mathrm{~F}}$ and $\mathrm{K}^{\mathrm{F}}(\mathrm{X})$ are unobserved market forecasts of $\mathrm{P}_{\mathrm{j}}^{*}$ and $\mathrm{K}^{\mathrm{S}}(\mathrm{X})$, and $\mathrm{n}$ is the length of the forward contract. The $\theta_{\mathrm{j}}$ are set equal in equations (3S) and (3F) as there is no reason to expect them to differ for short-term (e.g., 90-day) contracts.

The forecast error for the price of the commodity in question, $\mathrm{Z}_{1, \mathrm{t}, \mathrm{n}}$, is the difference between realized and forward prices:

$$
\mathrm{Z}_{1, \mathrm{t}, \mathrm{n}} \equiv \mathrm{P}_{1, \mathrm{t}}^{\mathrm{S}}-\mathrm{P}_{1, \mathrm{t}-\mathrm{n}, \mathrm{n}}^{\mathrm{F}}
$$

and for exchange rates, the forecast error is:

$$
\mathrm{Z}_{\mathrm{E}_{1 \mathrm{j}, \mathrm{t}, \mathrm{n}}} \equiv \mathrm{E}_{1 \mathrm{j}, \mathrm{t}}^{\mathrm{S}}-\mathrm{E}_{1 \mathrm{j}, \mathrm{t}-\mathrm{n}, \mathrm{n}}^{\mathrm{F}} \cdot
$$

Neglecting the constant term, the forecast error version of equation 3 is just the difference between equations $3 \mathrm{~F}$ and $3 \mathrm{~S}$, with a n-period lag:

$$
\begin{aligned}
\mathrm{Z}_{1, t, \mathrm{n}} & =\sum_{\mathrm{j}=1}^{\mathrm{M}} \theta_{\mathrm{j}} \cdot\left(\mathrm{Z}_{\mathrm{E}_{\mathrm{j} j \mathrm{t}, \mathrm{n}}}+\left[\mathrm{P}_{\mathrm{j}, \mathrm{t}}^{*}-\mathrm{P}_{\mathrm{j}, \mathrm{t}-\mathrm{n}, \mathrm{n}}^{* \mathrm{~F}}\right]\right)+\left[\mathrm{K}^{\mathrm{S}}\left(\mathrm{X}_{\mathrm{t}}\right)-\mathrm{K}^{\mathrm{F}}\left(\mathrm{X}_{\mathrm{t}-\mathrm{n}}\right)\right] \\
& =\sum_{\mathrm{j}=1}^{\mathrm{M}} \theta_{\mathrm{j}} \cdot \mathrm{Z}_{\mathrm{E}_{\mathrm{j} j \mathrm{t}, \mathrm{n}}}+\left[\mathrm{P}_{\mathrm{W}, \mathrm{t}}^{*}-\mathrm{P}_{\mathrm{W}, \mathrm{t}-\mathrm{n}}^{* \mathrm{~F}}\right]+\left[\mathrm{K}^{\mathrm{S}}\left(\mathrm{X}_{\mathrm{t}}\right)-\mathrm{K}^{\mathrm{F}}\left(\mathrm{X}_{\mathrm{t}-\mathrm{n}}\right)\right],
\end{aligned}
$$

where $\mathrm{P}_{\mathrm{W}, \mathrm{t}}^{*}=\sum_{\mathrm{j}=1}^{\mathrm{M}} \theta_{\mathrm{j}} \cdot \mathrm{P}_{\mathrm{j}, \mathrm{t}}^{*}$ is the "world" price level and, as $\mathrm{P}_{\mathrm{W}, \mathrm{t}-\mathrm{n}}^{* \mathrm{~F}}$ forecasts $\mathrm{P}_{\mathrm{W}, \mathrm{t}}^{*}$, the terms $\mathrm{P}_{\mathrm{W}, \mathrm{t},}^{*}-\mathrm{P}_{\mathrm{W}, \mathrm{t}-\mathrm{n}}^{* \mathrm{~F}} \equiv \mathrm{Z}_{\mathrm{p}, \mathrm{t}, \mathrm{n}}$ and $\mathrm{K}^{\mathrm{S}}\left(\mathrm{X}_{\mathrm{t}}\right)-\mathrm{K}^{\mathrm{F}}\left(\mathrm{X}_{\mathrm{t}-\mathrm{n}}\right) \equiv \mathrm{Z}_{\mathrm{K}, \mathrm{t}, \mathrm{n}}$ also are forecast errors. Since neither $\mathrm{Z}_{\mathrm{P}, \mathrm{t}, \mathrm{n}}$ nor $Z_{K, t, n}$ are observable, the forecast error version of equation 3 is written as:

$$
\mathrm{Z}_{1, \mathrm{t}, \mathrm{n}}=\text { constant }+\sum_{\mathrm{j}=1}^{\mathrm{M}} \theta_{\mathrm{j}} \cdot \mathrm{Z}_{\mathrm{E}_{1 \mathrm{j}}}+\mathrm{v}_{1 \mathrm{t}} \text {, }
$$

where $\mathrm{v}_{1 \mathrm{t}} \equiv \mathrm{Z}_{\mathrm{P}, \mathrm{t}, \mathrm{n}}+\mathrm{Z}_{\mathrm{K}, \mathrm{t}, \mathrm{n}}$ also is a forecast error.

If markets are weakly efficient, $\mathrm{K}^{\mathrm{F}}\left(\mathrm{X}_{\mathrm{t}-\mathrm{n}}\right)=\mathrm{E}\left[\mathrm{K}^{\mathrm{S}}\left(\mathrm{X}_{\mathrm{t}}\right) \mid \mathrm{I}_{\mathrm{t}-\mathrm{n}}\right]$ and $\mathrm{P}_{\mathrm{W}, \mathrm{t}-\mathrm{n}}^{* \mathrm{~F}}=\mathrm{E}\left(\mathrm{P}_{\mathrm{W}, \mathrm{t}}^{*} \mathrm{I}_{\mathrm{t}-\mathrm{n}}\right)$, where $E(\cdot)$ is the conditional expectation operator and $I_{t-n}$ is the information set at time $t-n$, and hence $\mathrm{Z}_{\mathrm{p}, \mathrm{t}, \mathrm{n}}, \mathrm{Z}_{\mathrm{K}, \mathrm{t}, \mathrm{n}}$, and $\mathrm{v}_{1 \mathrm{t}}$ are serially uncorrelated. Weak market efficiency implies, then, that all variables in equation 4 are serially uncorrelated. ${ }^{5}$ Given the potentially superior characteristics of forecast error data, equation 4 will be the center piece for the empirical implementation of the pricing model.

\section{PRELIMINARY TESTS ON THE DATA}

The spot gold price data consist of daily observations from January 1991 through June 2004 and the forward price data refer to 164 90-day contracts let at the beginning of each month during the same period, both in U.S. dollars. The daily spot and forward gold price data were kindly provided by Bill Cowan of Anglo Gold Ashanti Australia Limited. Spot and 90-day forward exchange rates between the U.S. dollar, the U.K. pound sterling, and the Japanese yen were obtained from the International Monetary Fund Data Bank (IMF) and cover the same period. Data for the DM exchange rates were obtained from the Bundesbank for the period 1991:01 to 1998:12, and data for the remaining exchange rates (and for the euro) were obtained from the IMF.

The spot and forward rates are generally very highly correlated, as is illustrated in the tabulations below: ${ }^{6}$

5 Lack of serial correlation in forecast errors also requires the absence of time-dependent risk premia; in what follows, that property is assumed to hold.

6 All estimates reported in this paper were made by WINRATS 6.2. 
Cross correlations of gold spot and forward Prices:

Monthly data from 1991:01 to 2004:05: 0.9989,

Cross correlations of DM (euro) spot and forward exchange rates:

Monthly data from 1991:01 to 2004:05: 0.9689,

Cross correlations of U.S. dollar spot and forward exchange rates:

Monthly data from 1991:01 to 2004:05: 0.9976,

Cross correlations of yen spot and forward exchange rates:

Monthly data from 1991:01 to 2004:05: 0.9996.

Note that the cross correlations for the DM (euro) are somewhat lower than for any of the other series. But when using only the Bundesbank data for the sub period 1991:01 to 1998:12, the results are:

Cross correlations of DM spot and forward exchange rates:

Monthly data from 1991:01 to 1998:12: 0.9977.

There apparently are errors in the IMF DM (euro) data, but the author has not been able to correct them other than to use the Bundesbank data for the DM spot and forward exchange rates for the 1991:01 through 1998:12 portion of the period under investigation. ${ }^{7}$

Because the forecast errors require a three month lag on the forward series, the useful data set is reduced to 161 overlapping (and hence serially correlated) observations. As the earlier study indicated that the U.K. "theta" is approximately zero, the pound sterling was designated currency 1 and the price of gold and all exchange rates were denominated in pounds.

As the empirical analysis focuses on the relation between exchange rates and the price of gold, and since the fundamentals are difficult to specify in advance (apart from "world" inflation, which may influence the appeal of gold as a store of value), we made no attempt to do so; accordingly, in estimating equation 4 , we assume that the exchange-rate forecast errors, $Z_{\mathrm{E}_{1 \mathrm{j}, \mathrm{t}, \mathrm{n}}}$ and those concerning gold-market fundamentals, $\mathrm{v}_{1 \mathrm{t}}$, are orthogonal.

\section{IIA. Market Efficiency Tests}

As was argued earlier, if the gold and foreign exchange markets are efficient, estimation of equation 4 is simplified as both the forecast errors and the residuals of equation 4 will be uncorrelated. Tests of both weak and semi-strong market efficiency were conducted.

\section{IIAi. Weak Market Efficiency}

The classic test for weak market efficiency is based on estimating the equation $\mathrm{P}_{\mathrm{i}, \mathrm{t}}^{\mathrm{S}}=\alpha+\beta \cdot \mathrm{P}_{\mathrm{i}, \mathrm{t}-3,3}^{\mathrm{F}}$ and testing the joint restriction $\alpha=0$ and $\beta=1$. But as market efficiency also requires serially uncorrelated forecast errors, the test for market efficiency was based on equation 5:

(5) $\mathrm{Z}_{\cdot \mathrm{t}, 3}=\gamma+\delta \cdot \mathrm{Z}_{, \mathrm{t}-3,3}$,

in which estimates of $\delta$ should not differ significantly from zero. Four $\chi^{2}$ statistics on the restriction $\delta=0$ based on OLS estimates of equation 5 for the 156 overlapping observations using White's (1980) robust standard error routine appear in Table 1 below. That restriction is not rejected except in the case of the $\chi^{2}$ statistic for the DM (euro), which is based on an OLS estimate of equation (5). ${ }^{8}$ This rejection may be due to the errors in the DM (euro) data that were mentioned

7 One wonders how much serious work at the IMF and elsewhere have been misled by these errors in basic data.

8 Were equation 5 to be estimated with a single lag on the independent variable, the expected value of the estimate of $\delta$ would be roughly 0.67 since two-thirds of the innovations in any observation on forecast errors tend to be 
earlier. The standard errors were re-estimated by the Hansen-Hodrick (1980) $(\mathrm{H}-\mathrm{H})$ method and the significance of $\mathrm{F}$ statistics on the $\delta=0$ restriction, also reported in Table 1 , are similar to the $\chi^{2}$ statistics except in the case of the DM (euro) where the restriction is not now rejected. In short, weak market efficiency is not rejected.

\section{IIAii. Semi-Strong Market Efficiency}

In the context of the model developed in section I, semi-strong market efficiency requires past gold price and exchange-rate forecast errors to be orthogonal with both the current gold price and exchange-rate forecast errors. The test for the gold market involves estimating the following equation:

(6) $\mathrm{Z}_{\mathrm{l}, \mathrm{t}+3,3}=\mu+\vartheta_{1} \cdot \mathrm{Z}_{1, \mathrm{t}, 3}+\sum_{\mathrm{i}=2}^{4} \vartheta_{1} \cdot \mathrm{Z}_{\mathrm{E}_{\mathrm{li}}, \mathrm{t}, 3}$,

and, for the $\mathrm{j}^{\text {th }}$ exchange rate, $\mathrm{Z}_{1}$ is replaced with $\mathrm{Z}_{\mathrm{E}_{\mathrm{lj}}}$. Semi-strong market efficiency is tested by the joint restriction that estimates of all four $\vartheta_{\mathrm{i}}$ are zero. Table 1 presents the four $\chi^{2}$ statistics on that joint restriction based on OLS robust-error estimates of equation 6 using the 153 overlapping observations; again the joint restriction is rejected only in the case of the DM (euro). However, the four $\mathrm{F}$ statistics are based on $\mathrm{H}-\mathrm{H}$ estimates of standard errors; semi-strong market efficiency is not rejected for gold or for any of the exchange rates, except marginally so for the DM (euro). In summary, neither weak market nor semi-strong market efficiency is rejected for any series, except possibly for the DM (euro).

common to adjoining observations. To avoid that bias, the independent variable was lagged three periods (i.e., one prediction period). 
TABLE 1

\section{MARKET EFFICIENCY TESTS ON FORECAST ERROR DATA:}

1991:1-2004:5

\begin{tabular}{|c|c|c|c|c|c|c|c|c|c|}
\hline \multirow[b]{2}{*}{ Statistic: } & \multicolumn{4}{|c|}{$\begin{array}{l}\text { Weak (Equation 5) } \\
\text { Forecast Error For: }\end{array}$} & & \multicolumn{4}{|c|}{$\begin{array}{l}\text { Semi-Strong (Equation 6) } \\
\text { Forecast Error For: }\end{array}$} \\
\hline & Gold & $\mathrm{DM}$ & Dollar & Yen & & Gold & $\mathrm{DM}$ & Dollar & Yen \\
\hline$\chi^{2}(1)^{\mathrm{a}}$ & 0.19 & 7.86 & 0.18 & 0.27 & $\chi^{2}$ & 1.24 & 11.47 & 0.37 & 1.62 \\
\hline P-value: & 0.59 & 0.02 & 0.67 & 0.61 & & 0.87 & 0.02 & 0.98 & 0.81 \\
\hline$F(1,156)^{b}$ & 0.23 & 2.19 & 0.75 & 0.08 & $F_{(1,153)}$ & 0.32 & 2.60 & 0.39 & 0.78 \\
\hline P-value: & 0.63 & 0.14 & 0.39 & 0.77 & & 0.87 & 0.04 & 0.82 & 0.54 \\
\hline
\end{tabular}

a All $\chi^{2}$ statistics are based on OLS estimates using White's (1980) Robust Error routine with 2 lags.

b All F statistics are based on Standard errors estimated by the Hansen-Hodrick (1980) method.

\section{ESTIMATES OF THE "THETAS" FOR THE WORLD GOLD MARKET}

As the pound sterling was designated currency 1 (the reference currency) and the gold prices and all exchange rates were denominated in that currency, there are but three parameters to estimate: $\theta_{\mathrm{DM}}, \theta_{\mathrm{US} \$}$, and $\theta_{\mathrm{Yen}}$. Equation 4 was estimated using all 161 overlapping observations with the standard errors estimated by the $\mathrm{H}-\mathrm{H}$ method. As a t test on the estimates of the $\theta_{\mathrm{j}}$ parameters, reported in panel A of Table 2, indicates that the unit-sum restriction cannot be rejected, that restriction was imposed and the results (again with standard errors estimated by the $\mathrm{H}-\mathrm{H}$ method) are summarized in panel B of Table 2. The restricted and unrestricted regressions were nearly identical-apart from an increase in the t statistics when using the $\mathrm{H}-\mathrm{H}$ method to estimate standard errors. Apparently the major gold producers, which include Australia, South Africa, and Russia, seem to have little power in the world gold market. Rather, that market is dominated by the U.S. dollar, DM (euro) and yen blocs, with the dollar having by far the largest weight. Note further that the estimates of $\theta_{\mathrm{DM}}, \theta_{\mathrm{US}}$, and $\theta_{\mathrm{Yen}}$. are all significant at the 0.00 per cent level. The low value of the Durbin-Watson statistic is due to the over-lapping nature of the date. Q statistics are not presented for the same reason. 
TABLE 2

\title{
OLS ESTIMATE OF EQUATION 4:
}

GOLD, 1991:01-2004:05

\author{
(Hansen-Hodrick Standard Errors)
}

\section{A. Unrestricted:}

$\begin{array}{lr}\text { Sum of } \theta_{\mathrm{j}} \text { Coefficients: } & 0.9641 \\ \text { Standard Error of Sum: } & 0.0923 \\ \text { T Statistic (against unity): } & -0.3886 \\ \text { P-Value: } & 0.6981\end{array}$

\section{B. Restricted}

PARAMETER

$\theta_{\mathrm{DM}}$

$\theta_{\mathrm{US \$}}$

$\theta_{\text {Yen }}$

\section{ESTIMATE}

0.1999

0.5779

0.2222
t-STATISTIC

2.8909

7.8432

4.0114
P-VALUE

0.0044

0.0000

0.0000

$$
\overline{\mathrm{R}}^{2}=0.3789 ; \quad \mathrm{SEE}=0.0497 ; \quad \mathrm{D}-\mathrm{W}=0.9892
$$

These results are quite different from those obtained in the earlier study, which covered the period 1983:01 through 1990:12. In that study, the estimates of $\theta_{\mathrm{DM}}, \theta_{\mathrm{US} \$}$, and $\theta_{\text {Yen }}$, obtained in the same way as those in Table 2, were 0.5339, 0.2759, and 0.1902, respectively. Apparently the power of the dollar bloc in the international gold market has grown over time, largely at the expense of the euro bloc. One possible explanation (but not a testable one) for that lies in the fact that, from the 1930s until the 1970s, U.S. citizens were prohibited from owning gold (except in the form of jewelry, etc.). As a result, gold bullion could not be part of U.S. individual portfolios for a long period of time.

There also is some evidence from the earlier study that the power of the dollar bloc of the international gold market was growing over time. To test whether the $\theta$ estimates vary over time, equation 4 was re-estimated in that study using two sub samples of equal length, which resulted in the following estimates: 0.5455 and 0.4995 for $\theta_{\mathrm{DM}}, 0.2472$ and 0.3045 for $\theta_{\mathrm{Us} \$}$, and 0.2073 and 0.1960 for $\theta_{\text {Yen }}$, respectively, for the sub samples 1983:01 through 1986:12 and 1987:01 through 1990:12. While the importance of the dollar bloc may have increased over the period analyzed in the earlier study (and that of Europe declined), in no case did the difference between the two estimates exceed the smaller of the two standard errors. 


\section{IIIA. "World" Inflation and the Price of Gold}

The estimate of equation 4 reported in Table 2 does not include any variables for the fundamentals, which are captured in equations $3 \mathrm{~S}$ and $3 \mathrm{~F}$ by $\mathrm{K}^{\mathrm{S}}\left(\mathrm{X}_{\mathrm{t}}\right)$ and $\mathrm{K}^{\mathrm{F}}\left(\mathrm{X}_{\mathrm{t}-3}\right)$. In the earlier study, a candidate, albeit an anemic one, was found to be "world" inflation, changes in which may affect the price of gold (but not necessarily exchange rates). The same test for the effect of "world" inflation was carried out in this study. As the U.S. dollar, the DM (euro) and yen blocs appear to totally dominate the world gold market, the "world" price level, $\mathrm{P}_{\mathrm{w}}^{*}$, was defined, as in the earlier study, as the natural logarithm of a weighted average of the European, U.S., and Japanese CPI price levels, the weights being the theta estimates reported in Table 2. The European price level was computed as a weighted average of German, U.K., Italian and French implicit GDP deflators. The weights, 0.3289, 0.2825, 0.1595 and 0.2291, respectively, were based on relative real GDPs during the second quarter of 2004. The quarterly "world" inflation rate was defined as $\Pi_{\mathrm{t}, 3} \equiv \mathrm{P}_{\mathrm{w}, \mathrm{t}}^{*}-\mathrm{P}_{\mathrm{w}, \mathrm{t}-3}^{*}$, and was converted to an annual rate, $\Pi_{\mathrm{t}}$. As inflation may have lagged effects, the inflation components of $\mathrm{K}^{\mathrm{S}}\left(\mathrm{X}_{\mathrm{t}}\right)$ and $\mathrm{K}^{\mathrm{F}}\left(\mathrm{X}_{\mathrm{t}-3}\right)$ were defined as $\gamma(\mathrm{L}) \cdot \Pi_{\mathrm{t}}$ and $\gamma(\mathrm{L}) \cdot \Pi_{\mathrm{t}-3}$. The inflation component of $\mathrm{v}_{1 \mathrm{t}}$ is $\gamma(\mathrm{L})\left(\Pi_{\mathrm{t}}-\Pi_{\mathrm{t}-3}\right)$, and was parameterized as:

$$
\gamma_{0} \cdot\left(\Pi_{t, 3}-\Pi_{t-3,3}\right)+\gamma_{1} \cdot\left(\Pi_{t-1,3}-\Pi_{t-4,3}\right)+\gamma_{2} \cdot\left(\Pi_{t-2,3}-\Pi_{t-5,3}\right) \text {. }
$$

Moreover, using the property of any polynomial $A(L)=\sum_{i=0}^{N} a_{i} \cdot L^{i}$ and any time series $Y_{t}$, that $\mathrm{A}(\mathrm{L}) . \mathrm{Y}_{\mathrm{t}}$ can be reparameterized in error correction form as:

$$
A(L) \cdot Y_{t}=\sum_{i=0}^{N-1}\left(\sum_{j-0}^{i} a_{j}\right) \cdot \Delta Y_{t-i}+A(1) \cdot Y_{t-N} \text {, }
$$

the inflation term $\gamma(\mathrm{L}) \cdot\left(\Pi_{\mathrm{t}}-\Pi_{\mathrm{t}-3}\right)$ is expressed, in the case two lags, as $\gamma_{0} \cdot \Delta\left(\Pi_{t}-\Pi_{t-3}\right)+\gamma_{1} \cdot \Delta\left(\Pi_{t-1}-\Pi_{t-4}\right)+\gamma(1) \cdot\left(\Pi_{t-2}-\Pi_{t-5}\right)$ which permits a direct estimate of $\gamma(1)$, the long run impact on the spot price of gold of a permanent change in the rate of "world" inflation.

The results of an OLS estimate of equation 4 augmented by the inflation variable with two lags are summarized in Table 3; the estimates of $\theta_{\mathrm{j}}$ are similar to those reported in Table 2, although some standard errors are slightly smaller. In an earlier study [Sjaastad (1996)] the results show that "world" inflation, as a fundamental, was quite an anemic one: a (permanent) rise in the (annual) rate of "world" inflation by one percentage point lead to a mere 0.78 per cent rise in the price of gold. The current study indicates that "world" inflation has a negative but statistically significant effect, albeit a very small one, on the price of gold. The results in the earlier study may have been influenced by the spike in "world" inflation in the very early 1980s.

In view of this curious result for the inflation variable, equation 4 was re-estimated using a consumer price index based inflation variable for the OECD countries (identified in the RATSOECD data base as E15CPI). The results are presented in Table 4. The estimates and significance of $\theta_{\mathrm{DM}}, \theta_{\mathrm{US} \$}$, and $\theta_{\text {Yen }}$. are very similar to those reported in Table 3, but the effect of inflation on the price of gold is still negative and even more significant. There seems to be no explanation for this negative effect. 
TABLE 3

OLS ESTIMATE OF EQUATION 4 WITH INFLATION VARIABLE:

GOLD, 1991:01-2004:05

(Hansen-Hodrick Standard Errors)

\section{A. Unrestricted}

$\begin{array}{lr}\text { Sum of } \theta_{\mathrm{j}} \text { Coefficients: } & 0.9237 \\ \text { Standard Error of Sum: } & 0.0908 \\ \text { t Statistic (against unity): } & -0.8411 \\ \text { P-Value: } & 0.4017\end{array}$

\section{B. Restricted}

PARAMETER

$\theta_{\mathrm{DM}}$

$\theta_{\text {US\$ }}$

$\theta_{\text {Yen }}$

$\gamma(1)$
LAG

$-$

$-$

$-$

2

\section{ESTIMATE}

0.2371

0.5238

0.2390

$-0.2581$

t-STATISTIC
3.6144
6.9461
4.4852
-2.3209

P-VALUE

0.0004

0.0000

0.0000

0.0217

$$
\overline{\mathrm{R}}^{2}=0.3513 ; \quad \mathrm{SEE}=0.0499 ; \quad \mathrm{D}-\mathrm{W}=1.0517
$$

\section{IIIB. A More General Formulation}

The overlapping nature of the forecast error data results in strong serial correlation in the data and in the residuals of OLS estimates based on those data; indeed, the partial auto-correlations for the forecast error data are high for up to seven or eight lags. This serial correlation suggests that lags may be useful even though weak market efficiency has not been rejected. A more general specification of equation 4, which incorporates lags, is the following:

(4') $\quad \alpha(L) \cdot \mathrm{Z}_{1, \mathrm{t}, \mathrm{n}}=$ constant $+\sum_{\mathrm{j}=2}^{\mathrm{M}} \Theta_{\mathrm{j}}(\mathrm{L}) \cdot \mathrm{Z}_{\mathrm{E}_{1 \mathrm{j}, \mathrm{t}, \mathrm{n}}}+\gamma(\mathrm{L}) \cdot\left(\Pi_{\mathrm{t}}-\Pi_{\mathrm{t}-3}\right)+\mathrm{v}_{1 \mathrm{t}} \cdot$ 
TABLE 4

OLS ESTIMATE OF EQUATION 4 WITH THE OECD INFLATION VARIABLE:

GOLD, 1991:01-2004:05

(Hansen-Hodrick Standard Errors)

A. Unrestricted

Sum of $\theta_{\mathrm{j}}$ Coefficients: $\quad 0.9128$

Standard Error of Sum: $\quad 0.0919$

t Statistic (against unity): $\quad-0.9489$

P-Value: $\quad 0.3442$

\section{B. Restricted}

\section{PARAMETER}

$\theta_{\mathrm{DM}}$

$\theta_{\mathrm{US} \$}$

$\theta_{\text {Yen }}$

$\gamma(1)$
LAG

$-$

$-$

$-$

2

$\overline{\mathrm{R}}^{2}=0.3516 ; \mathrm{SEE}=0.0499$;
ESTIMATE

0.2164

0.5436

0.2400

$-0.4281$
t-STATISTIC

3.2605

7.3323

4.3071

$-2.7418$
P-VALUE

0.0014

0.0000

0.0000

0.0069

Experimentation indicated that lags on the independent variables became redundant (i.e., $\Theta_{j}(L) \equiv \Theta_{j}$ ) once lags on the dependent variable were introduced; accordingly, the final effect on the spot price of gold of a permanent shock to the $j^{\text {th }}$ exchange rate is $\theta_{j} \equiv \Theta_{j} / \alpha(1)$, where $\alpha(1)=\sum_{i=0}^{I} \alpha_{i}$ and $\alpha_{0}=1$, and the long run reaction of the real spot price of gold to a permanent shock to "world" inflation is captured by the parameter $\Gamma \equiv \gamma(1) / \alpha(1)$. With this modification, equation 4' was estimated by OLS with lags being added until the estimate of $\alpha(1)$ stabilized (which occurred after the fourth lag) and the standard errors were estimated by the H-H technique; the inflation variable is the same as the one used in the regression reported in Table 3 . The results are reported in panel A of Table 5. ${ }^{9}$ Since the unit-sum restriction on the $\theta_{\mathrm{j}}$ was not rejected at the 25 per cent level of significance, equation 4 was re-estimated with that restriction imposed; the results for both the $\Theta_{j}$ and $\theta_{j}$ are reported in panel B of Table 5 .

\footnotetext{
${ }^{9}$ An iterative procedure was used to set the weights in the world price level equal to the estimates of the thetas. Equation (4') was not parameterized to provide direct estimates of $\theta_{j} \equiv \Theta_{j} / \alpha(1)$ and $\Gamma \equiv \gamma(1) / \alpha(1)$ since the resulting nonlinear equation would preclude using the Hansen-Hodrick (1980) method to estimate standard errors; instead, estimation was by OLS and the standard errors of $\theta_{j}$ and $\Gamma$ were obtained by Taylor expansions.
} 
TABLE 5

OLS ESTIMATE OF EQUATION 4' WITH INFLATION VARIABLES AND FOUR LAGS

ON DEPENDENT VARIABLE:

GOLD, 1991:01-2004:5

(Hansen-Hodrick Standard Errors)

\section{A. Unrestricted}

$\begin{array}{ll}\text { Sum of } \theta_{\mathrm{j}} \text { Coefficients: } & 1.0912 \\ \text { Standard Error of Sum: } & 0.1164 \\ \text { t Statistic (against unity): } & 0.7836 \\ \text { P-Value: } & 0.4346\end{array}$

\section{B. Restricted}

PARAMETER

$\Theta_{\mathrm{DM}}$

$\Theta_{\text {US\$ }}$

$\Theta_{\text {Yen }}$

$\alpha(1)$

$\theta_{\mathrm{DM}}$

$\theta_{\text {US\$ }}$

$\theta_{\text {Yen }}$

$\Gamma$

LAG
0
0
0

5

0

0

0

2

ESTIMATE
0.1250
0.3436
0.1850

t-STATISTIC
3.2719

7.1327

5.6360

$-9.2224$

3.1719

6.4886

5.6045

$-2.1941$
P-VALUE

0.0011

0.0000

0.0000

0.0000

0.0019

0.0000

0.2831

$-0.2556$

$\overline{\mathrm{R}}^{2}=0.4424 ; \mathrm{SEE}=0.0428 ; \mathrm{D}-\mathrm{W}=1.8535$

Despite first differencing of the dependent variable, the new estimates of equation $4^{\prime}$ dominate those reported in Tables 2, 3 and 4 . The $\overline{\mathrm{R}}^{2}$ has increased by one quarter to 0.44 and the standard error of estimate has declined to 0.043 from about 0.050 . The estimates of all thetasboth short and long-run-are significant at the 0.00 level, and the point estimates of $\theta_{\mathrm{DM}}, \theta_{\mathrm{US} \$}$, and $\theta_{\text {Yen }}$, are similar to the earlier estimates. The estimate of $\Gamma$, the effect of a permanent change in the rate of "world" inflation is still negative and quite significant.

It is clear from Table 5 that the U.S. dollar, the yen and the euro blocs dominate the international market. While a ten per cent appreciation of the DM (euro) against all other currencies increases the dollar price of gold by 1.9 per cent (and vice versa), the same appreciation of the yen increases the dollar price of gold by only 2.8 per cent. A ten per cent appreciation of the dollar against both currencies depresses the dollar price of gold by about five per cent, and vice versa. In the new estimates, "world" inflation still has a negative effect on the price of gold, and that effect remains significant. 


\section{SUMMARY OF THE MAIN RESULTS}

While we cannot claim that the empirical results for the case of gold can be generalized to other commodities, the main findings, based on an analysis of the gold and foreign exchange markets for the 1991-2004 period, are:

- The tests support the hypothesis of market efficiency for the world gold market during the 1991-2004 period.

- The use of serially uncorrelated forecast-error data greatly simplified the estimation process.

- While during the 1980s the world gold market was dominated by the European currency bloc which possessed over one half of the "market power" enjoyed by all participants in that market, in the 1990s and the early years of the current century, the dollar area appears to have become dominant (along with Japan). Accordingly, real appreciations or depreciations of the euro and the yen against the U.S. dollar have profound effects on the price of gold in all other currencies.

- The major gold producers of the world (Australia, South Africa, and Russia) appear to have no significant influence over the world price of gold.

- Gold no longer seems to be a store of value against "world" inflation, as was found in the earlier study; indeed, just the opposite was found in this study. 


\section{REFERENCES}

Clements, Kenneth and Larry Sjaastad. [1984] How Protection Taxes Exporters, Thames Essay, Trade Policy Research Center. London: Macmilan for the Trade Policy Research Center.

Dornbusch, Rudiger. [1987] "Exchange Rate Economics," Economic Journal, Vol. 97, No. 385; pp. 1-18.

Edwards, Sebastian. [1989] Real Exchange Rates, Devaluation, and Adjustment: Exchange Rate Policy in Developing Countries. Cambridge: The MIT Press.

Frenkel, Jacob. [1981] "The Collapse of Purchasing Power Parity During the 1970s," European Economic Review, Vol. 16; pp. 145-65.

Hansen, Lars Peter and R.J. Hodrick [1980] "Forward Exchange Rates as Optimal Predictors of Future Spot Rates: An Econometric Analysis," The Journal of Political Economy, Vol. 88; pp. 829-53.

Mussa, Michael. [1986] "Nominal Exchange Rate Regimes and the Behavior of Real Exchange Rates: Evidence and Implications," Carnegie-Rochester Conference Series on Public Policy, Vol. 25. Amsterdam: North-Holland Publishing Company; pp. 117-213.

Ridler, D. and C.A. Yandle. [1972] "A Simplified Method for Analyzing the Effects of Exchange Rate Changes on Exports of a Primary Commodity," IMF Staff Papers, Vol. 19; pp. 559-75.

Sjaastad, Larry A. [1985] "Exchange Rate Regimes and the Real Rate of Interest," in The Economics of the Caribbean Basin, Michael Connolly and John McDermott (eds), Praeger, New York; pp. 135-64.

(with Fabio Scacciavillani) [1996] "The Price of Gold and the Exchange Rates," Journal of International Money and Finance, December, 1996; reprinted in Meher Manzur (ed.), Exchange Rates, Interest Rates and Commodity Prices, Edward Elgar, 2002, and in Moonjoong Tcha (ed.), Gold and the Modern World Economy, Routledge, 2003.

White, Halbert. [1980] "A Heteroscedasticity-Consistent Covariance Matrix Estimator and a Direct Test for Heteroscedasticity," Econometrica, Vol. 48; pp. 817-38. 